\title{
First assessment of interchange of humpback whales between Oceania and the East coast of Australia
}

\author{
Claire Garrigue ${ }^{1}$, Trish Franklin ${ }^{2,7}$, Rochelle Constantine ${ }^{3}$, Kirsty Russell ${ }^{3}$, Daniel Burns ${ }^{3}$, Michael Poole $^{4}$, \\ Dave Paton ${ }^{2,5}$, Nan Hauser ${ }^{6}$, Marc Oremus $^{3}$, Simon Childerhouse ${ }^{7}$, Dave Mattila $^{8}$, Nadine Gibbs 9 , Wally Franklin ${ }^{2,13}$, \\ Jooke Robbins $^{10}$, Phil Clapham ${ }^{11}$ And C. Scott BaKer ${ }^{3,12}$ \\ Contacte-mail: op.cetaces@lagoon.nc
}

\begin{abstract}
The interchange of individual humpback whales between the wintering grounds of Oceania (South Pacific) and the east coast of Australia were documented by individual identification photographs collected from 1999 to 2004. Interchange was assessed using regional catalogues of fluke photographs, totalling 672 individuals from Oceania (represented by New Zealand, New Caledonia, Vanuatu, Fiji, Samoa, Tonga, Niue, Cook Island, French Polynesia and American Samoa) and 1,242 individuals from Hervey Bay and Byron Bay representing the southbound and the northbound migration along the east coast of Australia (EA). Overall, there were seven documented movements between EA and Oceania. Four instances of movement of four individuals were documented between EA and the closest breeding grounds of New Caledonia. A further three movements were recorded between EA and a small catalogue $(n=13)$ from the New Zealand migratory corridor. In contrast, during this same period, 20 cases of interchange were documented among nine breeding grounds: French Polynesia, Cook Islands, Niue, American Samoa, Samoa, Tonga, Fiji, Vanuatu and New Caledonia. The low level of interchange between Oceania and the east coast of Australia has important implications for understanding the stock structure and abundance of humpback whales in the South Pacific.
\end{abstract}

KEYWORDS: HUMPBACK WHALE; PHOTO-ID; MOVEMENTS; SITE FIDELITY; PACIFIC OCEAN; BREEDING GROUNDS

\section{INTRODUCTION}

Little is known of the movement of humpback whales (Megaptera novaeangliae) between the east coast of Australia (EA) and the winter breeding grounds of Oceania. The first information on movements of humpback whales in the South Pacific came from the Discovery marking and recovery programme between the 1950s and 1960s (Dawbin, 1959; 1964; Paton and Clapham, 2006). The results (Chittleborough, 1959; Dawbin, 1964) mainly highlighted the migration of humpback whales between Antarctic Area $\mathrm{V}\left(130^{\circ} \mathrm{E}\right.$ to $\left.170^{\circ} \mathrm{W}\right)$ and Australia and New Zealand, but also showed limited exchange between New Zealand and Australia (three marks recovered), Norfolk Island (one mark) and Fiji (two marks) and between Australia and Fiji (one mark). Dawbin (1966) concluded that the population of humpback whales passing along the east coast of Australia was part of the population of Area V known as 'Group V'.

Dawbin (1959) also reported the presence of whales in several island groups of Oceania as part of the Discovery marking programme used to track the journeys of humpback whales. However, some inherent problems with the programme included the limited marking of whales in Oceania, the fact that this technique relied on whales being killed to recover Discovery marks, and the lack of whaling activity in Oceania during this period (apart from some limited whaling in Tonga). These problems are likely to have contributed to the lack of any recorded movement between or within the islands of Oceania from the Discovery programme. It was not until photo-identification studies were started in the 1990s (Abernethy et al., 1992; Garrigue et al., 2001; Gibbs and Childerhouse, 2004; Hauser et al., 2000; Poole, 2002) that whale movements were able to be investigated within the region. Recent studies suggest that the South Pacific region contains several populations that intermingle to a variable, but probably small, degree (Constantine et al., 2007; Garrigue et al., 2002; 2000). Group $\mathrm{V}$ humpback whales have recently been divided into three sub-stocks known as Breeding Stock E(i), those wintering off the Australian east coast; E(ii), those wintering around New Caledonia and E(iii), those wintering around Tonga (Garrigue et al., 2006; IWC, 1998; Olavarria et al., 2007). The Australian east coast population, E(i), is thought to be the largest of these sub-stocks (Noad et al., 2008).

The regular comparison of flukes of humpback whales assembled in regional catalogues highlighted movements within Oceania (Garrigue et al., 2002; 2011) and allowed the estimation of rates of interchange to be made between the

\footnotetext{
${ }^{1}$ Opération Cétacés, BP 12827, 98802 Nouméa, New Caledonia.

${ }^{2}$ Southern Cross University Whale Research Centre, Southern Cross University, PO Box 157, Lismore, NSW 2480, Australia.

${ }_{3}^{3}$ School of Biological Sciences, University of Auckland, Private Bag 92019, Auckland, New Zealand.

${ }^{4}$ Marine Mammal Research, BP698 98728, Maharepa, Moorea, French Polynesia.

${ }^{5}$ Blue Planet Marine, PO Box 5535, Kingston, ACT 2604, Australia.

${ }^{6}$ Cook Islands Whale Research, Takuvaine Valley, PO Box 3069, Avarua, Rarotonga, The Cook Islands.

${ }^{7}$ University of Otago, PO Box 56, Dunedin, New Zealand.

${ }^{8}$ Hawaiian Islands Humpback Whale National Marine Sanctuary, Honolulu, Hawaii 96812, USA.

${ }^{9}$ Department of Conservation, PO Box 5086, Wellington, New Zealand.

${ }^{10}$ Provincetown Center for Coastal Studies, 5 Holway Avenue, Provincetown 02657, USA.

${ }^{11}$ Alaska Fisheries Science Center, National Marine Mammal Laboratory, 7600 Sand Point Way NE, Seattle, WA 98115, USA.

${ }^{12}$ Marine Mammal Institute, Oregon State University, 2030 SE Marine Science Dr, Newport, OR 97365, USA.

${ }^{13}$ The Oceania Project, PO Box 646, Byron Bay, NSW 2481, Australia.
} 
island groups. There has been opportunistic documentation of movement between Oceania and the migratory corridors of New Zealand and Australia (Garrigue et al., 2000) but the rate of exchange has only been calculated for New Zealand (Garrigue et al., 2002).

To assess the population size of humpback whales in the South Pacific, information is needed on the rate of exchange between the east coast of Australia and Oceania. Therefore, this project aimed to quantify and compare rates of interchange between Oceania and EA in order to better estimate abundance and describe stock structure of the humpback whale populations inhabiting the western and central parts of the South Pacific.

The results of comparisons between catalogues representing EA and nine regions of Oceania are reported here. More detailed analyses and comparisons utilising genetic tagging and differentiation techniques are being undertaken to better understand this interchange (e.g. differences in interchange between sexes, ages and directions of movements). Overall, it will provide a better understanding of the population structure of humpback whales in the South Pacific and allow for an improved and more robust estimate of abundance for humpback whales there.

\section{MATERIALS AND METHODS}

\section{Catalogues}

Dedicated humpback whale surveys have been conducted in the Oceania region since 1991 (South Pacific Whale Research Consortium, 2001; 2002; 2003; 2004; 2005). Photo-identification, acoustic and genetic data collection is connected to general information about group size, composition and behaviour. Only the fluke identification catalogues currently held by members and affiliates of the South Pacific Whale Research Consortium (SPWRC) working in Oceania and EA were considered in this study. Photo-identification of individual whales was conducted within each study site by each primary investigator. Following Katona et al. (1979), regional catalogues were compiled of all individual humpback whales identified from photographs of the unique markings on the ventral surface of their tail flukes. Original photographs were collected during the study period on both film and/or digitally. In the former case photographs were scanned at the highest possible level of resolution for digital storage and exchange. For the purpose of this study, a synoptic period was defined encompassing all the years from 1999 to 2004 and is hereafter referred to as the synoptic years.

The review presented in Garrigue et al. (2011) led to a fully reconciled catalogue for Oceania (the Oceania Catalogue). For the purposes of this exercise it is composed of whales' flukes from New Caledonia, Tonga (comprising Vava'u, Eua, Ha'apai, Niuatoputapu), Cook Islands, French Polynesia, Vanuatu, Fiji, Niue, Samoa, American Samoa and New Zealand.

The EA catalogue is composed of regional fluke catalogues of Hervey Bay and Byron Bay representing the southbound and northbound migrations of humpback whales respectively on the east coast Australian migratory corridor (Franklin and Franklin 1992-2006 ${ }^{14}$; Paton et al., 2011). These two reconciled regional catalogues from EA were

\footnotetext{
${ }^{14}$ Franklin, T. and Franklin, W. 1992-2006. A long-term study of the ecology and behaviour of humpback whales (Megaptera novaeangliae) in Hervey Bay by The Oceania Project: annual field reports. Queensland Environment Protection Agency (QEPA), Maryborough, Queensland. [Available from the author].
}

compared, leading to a single fully reconciled catalogue (EA catalogue) composed of unique individual humpback whales (Paton et al., 2011). The selected photographs were then compiled into two electronic catalogues (EA and Oceania) with attached information for each region.

\section{Quality control and matching process}

As is typical for humpback photo-identification research (Friday et al., 2000), all photographs used in the EA Oceania comparison were reviewed following a set of quality control standards in order to minimise bias in the dataset that will be used in the future to generate an abundance estimate for the Oceania population. All images were reviewed according to a standard set of quality control criteria that were originally developed for the SPLASH program in the North Pacific. This is a scoring system based on objective quality measures of the images that are irrespective of distinctiveness of the fluke (Calambokidis et al., 2001). It consists of five quality criteria to score photos from one to five in each category, agreed combinations of criteria are then used to accept or reject photos. All the images were graded from the highest quality (1) to the lowest quality (5). These five criteria categories were (i) proportion of the fluke visible, (ii) fluke angle, (iii) the lateral angle of the photographer, (iv) exposure quality and (v) contrast quality as described in Calambokidis et al. (2001). An image that received one or more four or five scores in any of the five categories was considered to be of insufficient quality for a representative comparison of resight rates between sites, and was therefore removed from the data set. To minimise errors in the dataset by inaccurate scoring of the images, an independent reviewer familiar with SPLASH protocol scored a subset of the dataset to determine consistency between the North and South Pacific projects.

Matching was undertaken using electronic images of similar size and resolution. The matching method used was a rational rather than exhaustive pair-wise comparison, as a full pair-wise comparison of EA to Oceania would have required over 860,000 matches. This meant that flukes in the Oceania catalogue were ranked (ordered) in a continuum from all white to all dark colouration. As in SPLASH, a single fluke photograph from EA was compared to all fluke photographs from Oceania starting at the relevant section of the catalogue, i.e. a dark fluke image was matched to all other dark fluke images but not to the all white fluke images. Once the reviewer was satisfied that no further match was possible, a new fluke was then matched to the appropriate part of the catalogue. A record was kept for each EA photograph of which sections of the Oceania catalogue it had been matched to and this was used to measure matching effort and allowed checks of the matching process to be made.

The Oceania catalogue was sorted into three approximately equal-sized groups to allow more efficient matching. Group one was composed of Cook Islands and French Polynesia, group two encompassed Tonga (only Vava'u) and group three comprised all the rest of the Oceania catalogue (New Caledonia, Niue, Fiji, Samoa, American Samoa, Vanuatu, Tonga (except Vava'u) and New Zealand). Once the catalogues were fully reconciled, all matches were confirmed by another person familiar with fluke matching.

\section{RESULTS}

Quality control and matching

The original datasets submitted for quality control screening contained 995 photographs for Oceania and 1,844 photographs 
Table 1

Summary of all photographs of unique individuals submitted for quality control by study site, East Australia and Oceania, between 1999 and 2004.

\begin{tabular}{|c|c|c|c|c|}
\hline Region & No. of photos submitted & No. of photos rejected & $\%$ of rejection & No. of photos accepted \\
\hline Byron Bay & 598 & 183 & 31 & 415 \\
\hline Hervey Bay & 1,246 & 375 & 30 & 871 \\
\hline Reconciled East Australia catalogue & & & & 1,242 \\
\hline French Polynesia & 230 & 107 & 47 & 159 \\
\hline Cook Islands & 90 & 64 & 71 & 36 \\
\hline Niue & 2 & 0 & 0 & 2 \\
\hline American Samoa & 39 & 8 & 21 & 31 \\
\hline Samoa & 2 & 1 & 50 & 1 \\
\hline Tonga & 422 & 140 & 33 & 282 \\
\hline Fiji & 2 & 0 & 0 & 2 \\
\hline Vanuatu & 6 & 0 & 0 & 6 \\
\hline New Caledonia & 185 & 25 & 14 & 160 \\
\hline New Zealand (NZ) & 17 & 4 & 24 & 13 \\
\hline Unreconciled Oceania catalogue & 995 & 349 & 35 & 692 \\
\hline Reconciled Oceania catalogue & & & & 672 \\
\hline
\end{tabular}

for EA. Overall, 32\% $(n=907)$ of the photographs had one or more four or five scores from the quality control criteria and thus, were excluded from the final dataset $(30 \%$ for EA and $35 \%$ for Oceania, Table 1). The rejection rate of the regional catalogues ranged from 0 to $71 \%$.

Table 1 presents the number of individual whales photoidentified in each regional study site and gives the final sizes of the two unreconciled catalogues after quality control had been undertaken. Following reconciliation, the two quality controlled catalogues for EA and Oceania contained 1,242 and 672 individually identified humpback whales respectively (Table 1) and these were then reconciled with each other to quantify the rate of interchange.

A rational pair-wise comparison of the two catalogues resulted in a total of 710,558 comparisons being made, $19 \%$ less than would have been done using a pair-wise comparison. Approximately three-quarters of the flukes in the EA catalogue $(76 \%)$ were compared to $86 \%$ of the Oceania catalogue. To test the accuracy of the matches a double blind test was conducted on a subset of the catalogues, including part of Byron Bay and part of New Caledonia (NC). An inexperienced matcher found the same results as the experienced matcher for the same images (two matches between $\mathrm{BB}$ and $\mathrm{NC}$ ).

\section{Interchange}

The comparison of the EA and Oceania catalogues resulted in seven matches between these two regions; four from the Oceania breeding grounds and three from the New Zealand migratory corridor (Fig. 1, Table 2). All four individuals from EA resighted in the breeding grounds of Oceania were first observed in New Caledonia (Table 3). Two of these were resighted in Hervey Bay, EA during the southern migration and the other two were resighted in Byron Bay, EA on the northern migration. All four whales were identified as males using molecular markers (Garrigue et al., 2004; Gilson et al., 1998). Three of the four resighted whales were observed in more than one year in New Caledonia with one observed in three different years, two sighted in two years and one identified on a single occasion. These whales were

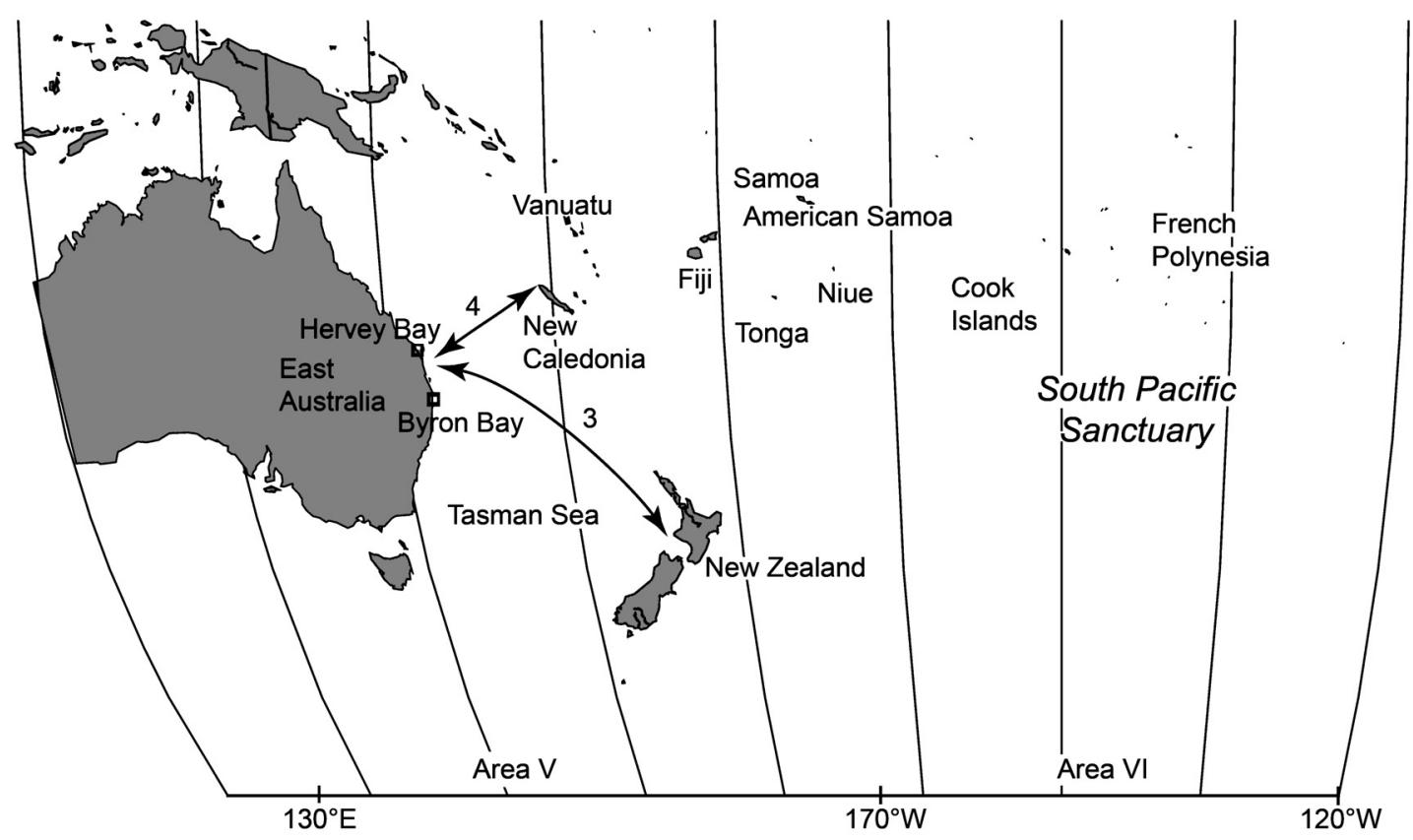

Fig. 1. Map of the study area showing the interchange of whales between east Australia and Oceania. 
Table 2

Movement by individual whales between East Australia and Oceania.

\begin{tabular}{|c|c|c|c|c|c|c|c|c|c|c|c|c|}
\hline Study sites & $\mathrm{BB}$ & HB & $\mathrm{NZ}$ & $\mathrm{NC}$ & VT & FI & $\mathrm{SA}$ & TG & NI & $\mathrm{CI}$ & FP & AS \\
\hline Byron Bay (BB) & & 44 & 0 & 2 & 0 & 0 & 0 & 0 & 0 & 0 & 0 & 0 \\
\hline Hervey Bay (HB) & & & 3 & 2 & 0 & 0 & 0 & 0 & 0 & 0 & 0 & 0 \\
\hline East Australia total & & & $3 *$ & 4 & 0 & $1 * *$ & 0 & 0 & 0 & 0 & 0 & 0 \\
\hline
\end{tabular}

*Discovery marking documented interchanges of three individuals between EA and NZ.

**Discovery marking documented interchange of one individual between Fiji and EA.

encountered in different types of social groups (single, pod of two and a reproductive pod) (Table 3 ). Interestingly two of these whales were first identified as young animals but not calves (this was assumed based on their apparent size). One of them was encountered with a female and was hypothesised to be a yearling as the microsatellite analysis identified them as a potential mother and calf pair (Garrigue et al., 2004).

Of the three whales matched between the EA catalogue and the New Zealand migratory corridor, two were observed only once at each site and the third whale was observed three times in Hervey Bay, EA (Table 3). Interestingly these three whales were sighted in Cook Strait, New Zealand during the northbound migration in 2004 and sighted in Hervey Bay during the southbound migration (Table 3 ). Two resights occurred in the same year (2004) with intersight intervals of 87 and 92 days. Both were sexed as male, one by molecular analysis and the other by field observation supported by photo-identification of the genital area (TF).

\section{DISCUSSION}

\section{Quality control and matching}

It is important in large-scale matching projects to consider the most efficient and unbiased design for quality control and the structure of the comparison. The use of a system that allows evaluation of the quality of the photograph, rather than the distinctiveness of the marks on the flukes reduces bias towards distinctive whales (Friday et al., 2000) and improves accuracy for population estimation (Hammond, 1990). The use of the SPLASH scoring system (Calambokidis et al., 2001) showed the efficacy of quality control even though the South Pacific whales are predominantly white ( $86 \%$ ca. $10-20 \%$ in the North Pacific) and the North Pacific whales are predominantly black. The difference in colouration meant that we relied on patterns on the underside of the flukes as well as marks on the trailing edge, whereas matching of the North Pacific whales relied more on marks on the trailing edge.

The rational pair-wise comparison saved approximately $20 \%$ of the matching time in this project, compared to a full comparison. Given that it would be extremely unlikely that a predominantly black fluke photograph would match a fluke that is predominantly white, we considered that the rational pair-wise method was a more efficient, yet still accurate, method.

\section{Interchange and isolation}

The results presented here represent the first systematic comparison of individual movement across the migratory corridors and wintering grounds of humpback whales thought to feed in Areas V and VI $\left(130^{\circ} \mathrm{E}-110^{\circ} \mathrm{W}\right)$ of the Antarctic. The three matches documented between EA and New Zealand suggests an even stronger connection between these two corridors than previously thought based on Discovery marking and recovery (Table 3). However, the catalogue for the New Zealand corridor remains small (reflecting the low level of recovery of this stock (Childerhouse and Gibbs, 2006)), and the relatively high rate could reflect an episodic, rather than ongoing, exchange.

Only four individuals were resighted between EA and New Caledonia, the closest breeding ground in Oceania. All four whales were male but the interchange is unlikely to be sex-biased as few whales resighted outside of the synoptic period were female (Garrigue et al., 2000; CG, DP and TF, unpublished data). These movements are not age-biased as both young, independent whales and adult whales were resighted. The movements also do not appear to be related to a specific social grouping as the resighted whales were recorded in a mixture of group types including single whales, members of pair, an escort of a mother and calf pair and individuals involved in competitive group.

With only four individuals resighted between EA and the breeding grounds of Oceania the level of interchange was

Table 3

Direction of movement of individual humpback whales between the study sites of East Australia and Oceania with information on sex, age class and social group composition.

\begin{tabular}{|c|c|c|c|c|c|}
\hline First region & Direction & Second region & Sex & Age & Social group composition \\
\hline $\begin{array}{l}\text { New Caledonia } \\
1995,1999 \\
2000,2005\end{array}$ & East & $\begin{array}{c}\text { Hervey Bay } \\
2000,2001 \\
2002\end{array}$ & $\begin{array}{l}\text { Male } \\
\text { Male }\end{array}$ & $\begin{array}{l}\text { Young, then adult } \\
\text { Adult }\end{array}$ & $\begin{array}{l}\text { Single, pod of } 6 \text {, pod of } 2 \\
\text { Pod of } 2, \text { pod of } 3 \text {, reproductive pod }\end{array}$ \\
\hline $\begin{array}{l}\text { New Caledonia } \\
1999,2000,2001 \\
2001\end{array}$ & East & $\begin{array}{c}\text { Byron Bay } \\
2002 \\
2002\end{array}$ & $\begin{array}{l}\text { Male } \\
\text { Male }\end{array}$ & $\begin{array}{l}\text { Yearling, adult } \\
\text { Adult }\end{array}$ & $\begin{array}{l}\text { Yearling }+ \text { mother, single, pod of } 2 \text {, reproductive pod } \\
\text { Pod of } 2 \text {, reproductive pod }\end{array}$ \\
\hline $\begin{array}{l}\text { Hervey Bay } \\
1997,1999,2002\end{array}$ & & $\begin{array}{l}\text { New Zealand } \\
2004\end{array}$ & Unknown & Adult & Single, pod of 2 , pod of 5 \\
\hline $\begin{array}{l}\text { New Zealand } \\
2004 \\
2004\end{array}$ & & $\begin{array}{c}\text { Hervey Bay } \\
2004 \\
2004\end{array}$ & $\begin{array}{l}\text { Male } \\
\text { Male }\end{array}$ & $\begin{array}{l}\text { Adult } \\
\text { Adult }\end{array}$ & $\begin{array}{l}\text { Pod of } 3 \text {, pod of } 2 \\
\text { Mother, calf and escort, pod of } 2\end{array}$ \\
\hline
\end{tabular}


surprisingly small, given the relatively large catalogues used in this comparison spanning a six-year period; this provides strong evidence for subdivision within Breeding Stock E (formerly Group V). By comparison, the rate of interchange within the different regions of Oceania for the same period is five times higher, highlighting the low rate of interchange between Oceania and EA on both the northern and southern migrations. The 20 resightings of whales among breeding grounds of Oceania indicate a limited, but not insignificant, interchange across this vast region (Garrigue et al., 2011).

It is worth noting that all the interchanges between EA and Oceania were found with the nearest of the Oceania breeding grounds in New Caledonia. This area exhibited roughly the same rate of exchange between the other Oceania grounds for the same period (with five matches all located in the south-western part of the Pacific including Vanuatu and Tonga) (Garrigue et al., 2011). With this level of interchange between New Caledonia and the rest of Oceania it is surprising that there were no matches between EA and any of the other regions within Oceania during the six-year synoptic period. It must be noted that other matches between EA and Oceania have been found outside the synoptic period, e.g., Tonga and Ballina, EA (DB, unpublished data). Nevertheless, this study included a large number of photoidentified individuals from several major breeding grounds and two important migratory corridors (EA and New Zealand) therefore, the results of this study are likely to be representative of the primary patterns of movement between EA and Oceania. Future work will focus on planning for an expansion of the synoptic period to investigate matches over a longer time frame.

\section{ACKNOWLEDGEMENTS}

This work is a South Pacific Whale Research Consortium contribution. We acknowledge Fonds Pacifique for funding this project through Opération Cétacés and the South Pacific Whale Research Consortium. We thank John Calambokidis from the Cascadia Research Center for his advice and assistance, Jessie Huggins from the Cascadia Research Center for her assistance in the coding process of the photos and Chris Conroy for assistance in preparation of some of the catalogues. The study of humpbacks undertaken in Oceania by the SPWRC is partly supported by the International Fund for Animal Welfare (IFAW). The longterm study of humpbacks in Hervey Bay being conducted by Trish and Wally Franklin is supported by the Oceania Project and the International Fund for Animal Welfare (IFAW). We thank the two anonymous reviewers for providing helpful comments that improved this manuscript.

\section{REFERENCES}

Abernethy, R.B., Baker, C.S. and Cawthorn, M.W. 1992. Abundance and genetic identity of humpback whales (Megaptera novaeangliae) in the southwest Pacific. Paper SC/44/O20 presented to the IWC Scientific Committee, June 1992 (unpublished). 46pp. [Paper available from the Office of this Journal].

Calambokidis, J., Steiger, G.H., Straley, J., Herman, L.M., Cerchio, S., Salden, D., Urbán R, J., Jacobsen, J.K., von Zeigesar, O., Balcomb, K.C., Gabriele, C.M., Dahlheim, M.E., Uchida, S., Ellis, G., Miyamura, Y., Ladrón de Guevara P, P., Yamaguchi, M., Sato, F., Mizroch, S.A., Schlender, L., Rasmussen, K., Barlow, J. and Quinn II, T.J. 2001. Movements and population structure of humpback whales in the North Pacific. Mar. Mammal Sci. 17(4): 769-94.

Childerhouse, S. and Gibbs, N. 2006. Preliminary report for Cook Strait humpback whale survey winter 2006. Unpublished report WGNHO264433 to Department of Conservation, PO Box 10-420, Wellington, New Zealand. 6pp. [Available from the author].
Chittleborough, R.G. 1959. Australian marking of humpback whales. Norsk Hvalfangsttid. 48(2): 47-55. [In Norwegian and English].

Constantine, R., Russell, K., Gibbs, N., Childerhouse, S. and Baker, C.S. 2007. Photo-identification of humpback whales (Megaptera novaeangliae) in New Zealand waters and their migratory connections to breeding grounds of Oceania. Mar. Mammal Sci. 23(3): 715-20.

Dawbin, W.H. 1959. New Zealand and South Pacific whale marking and recoveries to the end of 1958. Norsk Hvalfangsttid. 48(5): 213-38.

Dawbin, W.H. 1964. Movements of humpback whales marked in the southwest Pacific Ocean 1952 to 1962. Norsk Hvalfangsttid. 53(3): 6878.

Dawbin, W.H. 1966. The seasonal migratory cycle of humpback whales pp.145-70. In: Norris, K.S. (eds). Whales, Dolphins, and Porpoises. University of California Press, Berkeley and Los Angeles. xv+789pp.

Friday, N., Smith, T., Stevick, P. and Allen, J. 2000. Measurement of photographic quality and whale distinctiveness for the photographic identification of humpback whales, Megaptera novaeangliae. Mar. Mammal Sci. 16(2): 355-74.

Garrigue, C., Aguayo, A., Amante-Helwig, V.L.U., Baker, C.S., Caballero, P., Clapham, P., Constantine, R., Denkinger, J., Donoghue, M., FlorezGonzalez, L., Greaves, J., Hauser, N., Olavarria, C., Pairoa, C., Peckham, H. and Poole, M. 2002. Movements of humpback whales in Oceania, South Pacific. J. Cetacean Res. Manage. 4(3): 255-60.

Garrigue, C., Constantine, R., Poole, M.M., Hauser, N., Clapham, P., Donoghue, M., Russell, K., Paton, D., Mattila, D.K., Robbins, J. and Baker, C.S. 2011. Movement of individual humpback whales between wintering grounds of Oceania (South Pacific), 1999 to 2004. J. Cetacean Res. Manage. (special issue 3): 275-281.

Garrigue, C., Dodemont, R., Steel, D. and Baker, C.S. 2004. Organismal and 'gametic' capture recapture using microsatellite genotyping confirm low abundance and reproductive autonomy of humpback whales on the wintering grounds of New Caledonia (South Pacific). Mar. Ecol. Prog. Ser. 274: 251-62.

Garrigue, C., Forestell, P., Greaves, J., Gill, P., Naessig, P. and Baker, C.S 2000. Migratory movement of humpback whales (Megaptera novaeangliae) between New Caledonia, East Australia and New Zealand. J. Cetacean Res. Manage. 2(2): 101-10.

Garrigue, C., Greaves, J. and Chambellant, M. 2001. Characteristics of the New Caledonian humpback whale population. Mem. Queensl. Mus. 47(2): 539-46.

Garrigue, C., Olavarria, C., Baker, C.S., Steel, D., Dodemont, R., Constantine, R. and Russell, K. 2006. Demographic and genetic isolation of New Caledonia (E2) and Tonga (E3) breeding stocks. Paper SC/A06/HW19 presented to the IWC Workshop on Comprehensive Assessment of Southern Hemisphere Humpback Whales, Hobart, Tasmania, 3-7 April 2006 (unpublished). 10pp. [Paper available from the Office of this Journal].

Gibbs, N. and Childerhouse, S. 2004. First report for Cook Strait humpback whale survey winter 2004. Unpublished report WGNCO-45765. [Available from Department of Conservation, PO Box 5086, Wellington, New Zealand].

Gilson, A., Sylvanen, M., Levine, K. and Banks, J. 1998. Deer gender determination by polymerase chain reaction: validation study and application to tissues, bloodstains and hair forensic samples from California. Calif. Fish Game 84(4): 159-69.

Hammond, P.S. 1990. Heterogeneity in the Gulf of Maine? Estimating humpback whale population size when capture probabilities are not equal. Rep. int. Whal. Commn (special issue) 12: 135-39.

Hauser, N., Peckham, H. and Clapham, P. 2000. Humpback whales in the Southern Cook Islands, South Pacific. J. Cetacean Res. Manage. 2(3): 159-64.

International Whaling Commission. 1998. Report of the Scientific Committee. Annex G. Report of the sub-committee on Comprehensive Assessment of Southern Hemisphere humpback whales. Rep. int. Whal. Commn 48:170-82.

Katona, S., Baxter, B., Brazier, O., Kraus, S., Perkins, J. and Whitehead, H. 1979. Identification of humpback whales by fluke photographs. pp.3344. In: Winn, H.E. and Olla, B.L. (eds). Behaviour of Marine Mammals, Vol. 3: Cetaceans. Plenum Press, New York and London. i-xix +438 pp.

Noad, M.J., Dunlop, R.A., Paton, D. and Cato, D.H. 2008. An update of the east Australian humpback whale population (E1) rate of increase. Paper $\mathrm{SC} / 60 / \mathrm{SH} 31$ presented to the IWC Scientific Committee, June 2008, Santiago, Chile (unpublished). 13pp. [Paper available from the Office of this Journal].

Olavarria, C., Baker, C.S., Garrigue, C., Poole, M., Hauser, N., Caballero, S., Florez-Gonzalez, L., Brasseur, M., Bannister, J., Capella, J., Clapham, P., Dodemont, R., Donoghue, M., Jenner, C., Jenner, M.N., Moro, D., Oremus, M., Paton, D. and Russell, K. 2007. Population structure of South Pacific humpback whales and the origin of the eastern Polynesian breeding grounds. Mar. Ecol. Prog. Ser. 330: 257-68. 
Paton, D.A., Brooks, L., Burns, D., Franklin, T., Franklin, W., Harrison, P. and Baverstock, P. 2011. Abundance of east coast Australian humpback whales (Megaptera novaeangliae) in 2005 estimated using multi-point sampling and capture-recapture analysis. J. Cetacean Res. Manage. (special issue 3): 253-259.

Paton, D.A. and Clapham, P.J. 2006. An assessment of Southern Hemisphere humpback whale population structure and migratory interchange based on Discovery mark data. Paper SC/A06/HW33 presented to the IWC Workshop on Comprehensive Assessment of Southern Hemisphere Humpback Whales, Hobart, Tasmania, 3-7 April 2006 (unpublished). 19pp. [Paper available from the Office of this Journal].

Poole, M.M. 2002. Occurrence of humpback whale (Megaptera novaeangliae) in French Polynesia 1988-2001. Paper SC/54/H14 presented to the IWC Scientific Committee, April 2002, Shimonoseki, Japan (unpublished). 12pp. [Paper available from the Office of this Journal].

South Pacific Whale Research Consortium. 2001. Report of the Annual Meeting of the South Pacific Whale Research Consortium, 9-12 April 2001, Auckland, New Zealand. 14. 14pp. [Available from: South Pacific Whale Research Consortium, PO Box 3069, Avarua, Rarotonga, Cook Islands].
South Pacific Whale Research Consortium. 2002. Report of the Annual Meeting of the South Pacific Whale Research Consortium, 24-28 February 2002, Auckland, New Zealand. Paper SC/54/O14 presented to the IWC Scientific Committee, April 2002, Shimonoseki, Japan (unpublished). 12pp. [Paper available from the Office of this Journal].

South Pacific Whale Research Consortium. 2003. Report of the Annual Meeting of the South Pacific Whale Research Consortium, 13-17 February 2003, Auckland, New Zealand. Paper SC/55/SH2 presented to the IWC Scientific Committee, May 2003, Berlin (unpublished). 11pp. [Paper available from the Office of this Journal].

South Pacific Whale Research Consortium. 2004. Report of the Annual Meeting of the South Pacific Whale Research Consortium, 2-6 April 2004, Byron Bay, NSW, Australia. Paper SC/56/SH7 presented to the IWC Scientific Committee, July 2004, Sorrento, Italy (unpublished). 9pp. [Paper available from the Office of this Journal].

South Pacific Whale Research Consortium. 2005. Report of the Annual Meeting of the South Pacific Whale Research Consortium, Auckland, New Zealand, 11-13 March 2005. Paper SC/57/SH9 presented to the IWC Scientific Committee, June 2005, Ulsan, Korea (unpublished). 11pp. [Paper available from the Office of this Journal]. 